\title{
Study of the Functions of English Grammatical Metaphor from the Perspective of Cognition
}

\author{
Gao Song \\ School of Foreign Languages \\ University of Jinan \\ Jinan, China 250022
}

\begin{abstract}
Grammatical metaphor is a language device that can be used in expressing ideas and organizing English texts. By using grammatical metaphor flexibly, people may make their expressions vivid and lively, embodying the image function of language. The proper use of grammatical metaphor may exhibit the conceptualization feature of language and the differences of various text types, conveying meanings correctly. Furthermore, the use of grammatical metaphor in particular contexts may not only embody the shift of people's cognitive domain, making their expressions colorful, but also displays the interactivity of people's cognition, language and the relevant communicative contexts.
\end{abstract}

Keywords-cognition; grammatical metaphor; function; image; conceptualization

\section{INTRODUCTION}

The grammatical metaphor is a linguistic concept proposed by systemic functional linguist Halliday [1] ${ }^{\mathrm{P} 342}$, referring to those metaphorical language expressions that are inconsistent with the reality and involves the grammatical transformation of linguistic structure with the same meaning, that is, "different signifiers, same signified". From a functional perspective, Halliday divides grammatical metaphor into conceptual metaphor and interpersonal metaphor. Conceptual metaphor is to metaphorize the process within the transitivity system, which metaphorizes one process to another. Interpersonal metaphor is mainly achieved through the change of mood system and modality system. Specifically, people can use inconsistent tones or modal expressions to metaphorize some grammatical forms according to contexts. Since Halliday proposed this concept, some scholars have explored the textual functions of grammatical metaphor (Fan Wenfang [2]; Xiong xi [3]; Sun Chengrong et al [4]; Sun Yi et al [5].) Their study found that the application of grammatical metaphor can enhance the semantic relation and correlation of discourse, people should learn to observe and use grammatical metaphor expressions to improve their language expression level and creativity. However, few scholars at home and abroad have studied the functions of English grammatical metaphor from the perspective of cognition. Therefore, this paper intends to explore the cognitive functions of English grammatical metaphor on the basis of existing studies.

\section{THE FUNCTIONS OF ENGLISH GRAMMATICAL METAPHOR FROM THE PERSPECTIVE OF COGNITION}

From the perspective of cognition, the functions of English grammatical metaphor can be embodied in the following four aspects.

\section{A. Bringing into Play the Imagery Function of Language}

Cognitive linguistics believes that imagery is an essential component of human cognition, a thinking model that the concept formed in the brain, and a subjective ability that people observe the objective situation and interpret contents in different ways, which can help people cognize events in a dynamical manner [6]. For the same objective thing, people can highlight different sides and form different imageries by choosing different observation targets from different perspectives, thus producing different ways of language expression [7] ${ }^{\mathrm{P} 229}$. Therefore, the description of language meaning cannot be separated from imagery, and the conceptual content of each language expression is constructed by an accompanying imagery. We can come to a conclusion that grammar is imagery-related, and humans generalize the characteristics of events or concretize abstract concepts through imageries. This is the basic way for humans to understand the world. Grammatical metaphor embodies this cognitive approach. From the perspective of cognition, both nominalized grammatical metaphor and verbalized grammatical metaphor have imagery functions. As is known to all, nominalized words can represent things, including the physical world and the conceptual world, and can refer to something definitely. While expressing things, nominalized words also have some imagery functions, which bridge the gap between the human experience world and the conceptual world. The usage of verbalized word metaphor can also evoke certain imagery, and in particular the verbs expressing specific behaviors and events are most likely to evoke imageries in the human brain [8] ${ }^{\mathrm{p} 336}$. In a specific context, when a noun is converted into a verb, it can describe the things more specifically and vividly, that is, the abstract conceptual behavior can be transformed into a clear, concrete, and stereoscopic image, and the static referential meaning of a noun can be changed into a dynamic description. Therefore, people should use grammatical metaphor reasonably in language expression, give full play to its unique imagery 
functions, and express meaning concretely and vividly. Here are some examples:

(1)My father was often visited by important men who consulted him about affairs in the town. He was respected for his good judgment. He liked to invite sensible friends and neighbors over to our home to talk and always took care to bring up a useful topic for discussion that might improve the minds of his children.

We can see that there are two nominalized grammatical metaphors in (1). One is "He was respected for his good judgment." Its congruent form is "He was respected for he judged well." The other is "...bringing up a useful topic for discussion that might improve the minds of his children." Its congruent form is "...bringing up a useful topic that could be discussed, which might improve the minds of his children." These two nominalized grammatical metaphors are exquisite. They not only help make the sentences cohesive, but also give into full play the imagery function of the language. These sentences depict a good father who is keen to judge, likes to discuss and is good at guiding children. Let's see the following examples:

(2a)Whether I sleep with the window open is determined by the weather condition.

\section{(2b)I sleep with the window open unless it's really cold.}

We can see that the sentences of (2a) and (2b) express the same semantics. The sentence of $(2 b)$ is the congruent form of language, which use the conjunction "unless" to represent conditional relation, while the sentence of (2a) is the verbalized grammatical metaphor, which use the verb "determine" to represent the same logical relation. Compared with the sentence of $(2 b)$, the sentence of (2a) has a more subjective and visualized description, which can better reflect the imagery function of the language.

When people express their thoughts in English, they often adopt an avoidance strategy for fear of mistakes. In terms of language output, they mostly use simple sentences such as single sentences and short sentences in oral or written expressions, and rarely use complicated ones. As a result, their language output is often dull and lacks imageries. Grammatical metaphor is an effective means of discourse organization. When people apply it to oral or written expressions, their language will become more dynamitic and vivid. Therefore, people should consciously foster an awareness of the use of grammatical metaphor so that they can appropriately use grammatical metaphor in language output.

\section{B. Embodying the Conceptual Characteristics of Language}

Cognitive linguistics thinks that concept is a thinking model reflecting the key characteristic and essential attribute of the objective things, and that language symbols do not correspond to the objective external world, but are consistent with the conceptual structure forming under the cognitive participation. Language is the symbolization towards conceptualization, and the formation of meaning is the process of conceptualization, which is closely related to people's experience perception and cognitive approach [9].
Conceptualization involves the characteristics of people's cognition of objective things. Different people may have different cognitive perspectives on the same phenomenon, which may affect the syntactic behavior of the words they use. In other words, people can use different grammatical structures when coding the conceptualization of the same situation of language, and the semantics between these grammatical structures are different [10]. The conceptual function of language is embodied by the transitive system. In this system, language can reflect the various processes of human activities, the participants of processes, and the environmental components associated with processes. Human activities can be depicted as six processes: the material process, the psychological process, the relationship process, the verbal process, the behavior, and the existing process [1]. When one process is metaphorized into another, grammatical metaphor is produced. Therefore, grammatical metaphor is an effective means to embody the functions of language concepts, and its main conceptual function is to abstract or concretize the human experience. Abstraction can be represented by nominalization at the lexical grammar level, that is, experiential construction metaphor represented by common clauses in some languages is transformed into participants represented by nouns or noun phrases. Concretization can be reflected by verbalization at the vocabulary syntax level, that is, using verbs in some registers instead of other parts of speech to express the meaning that is generally not expressed by the verbs [11] ${ }^{\mathrm{P} 6}$. In the process of nominalization or verbalization, the conceptual functions of language can be fully reflected.

From the perspective of cognition, the formation of concepts is closely related to people's classification of objective things, which has a certain degree of subjectivity. In the language expression, it means different language structures reflect different concepts. Therefore, in order to express different conceptual meanings, people distinguish different language styles. The study found that the grammatical metaphor, which embodies the conceptual features of language conceptualization, has different distribution characteristics in discourses of different genres. Therefore, grammatical metaphor has the function of distinguishing different styles. Wang Jinjun [12] once conducted a statistical analysis on 100 English texts of different styles. He found that the order of proportions of nominalized grammatical metaphors in discourse is consistent with the order of formal levels of these texts, namely the highest level in Legal and scientific formal discourses, with the largest proportion of nominalized grammatical metaphors; the formalization of journalistic and fiction styles is centered, and the proportion of nominalized grammatical metaphors among them is also in the middle; the style of fairy tale fables have the lowest level of formality and the smallest proportion of its nominalization. We can see that the higher the frequency of nominalized grammatical metaphor, the higher the formal degree of the corresponding discourse will be. Therefore, people should use the grammatical metaphor flexibly in different genres to fully embody the conceptual features of the language and its differences in different genres in order to convey the 
semantics and complete the communicative intentions properly. Here are some other examples:

(3a)In bridging river valleys, the early engineers built many notable masonry viaducts of numerous arches. [1] ${ }^{\mathrm{P} 350}$

(3b)In the early days when engineers had to make a bridge across a valley and the valley had a river flowing through it, they often built viaducts, which were constructed of masonry and had numerous arches in them; and many of these viaducts became notable. [1] ${ }^{\text {P351 }}$

We can see that these two sentences Halliday used have the same content of semantic information, but the sentence of (3a) is a grammatical metaphor with a nominalized word bridging. This sentence has fewer words, but is more cohesive and formal, which meets the stylistic requirements of scientific and technological texts; while the sentence of (3b) is a congruent form, which has more words. There are six clauses in the sentence of (3b), but they are very simple and much informal. The whole sentence is a spoken language which does not conform to the stylistic requirements of scientific texts. Therefore, in the process of language output, people should consider the requirements of style, use grammatical metaphor flexibly, and choose appropriate language expressions to accurately express ideas and achieve the goal of communication.

\section{Reflecting the Conversion of Cognitive Domains}

Cognitive linguists use the cognitive domain to describe the conceptual domain involved in the semantic structure. From the perspective of cognition, the various concepts and knowledge systems possessed by human beings can form a hierarchical cognitive domain network, that is, people's encyclopedic knowledge systems are the background that people must refer to when describing the meaning of any language structure. In this network of cognitive domains, people refer to the concepts of cognitive things to recognize unknown things and form concepts [13]. In general, the description of the meaning of a linguistic structure is based on multiple cognitive domains. Therefore, the cognitive domain can be viewed as a network of knowledge that is linked to multiple cognitive domains related to a linguistic structure [14] p84-86. For example, people's complete understanding of the semantics of "a football" involves not only the shape of its entity, but also its color, size, material, and the rules that football involves as a sport. These cognitive domains constitute a knowledge network. In this cognitive process, one basic cognitive ability that people use is the analogy ability. Analogical activities can occur between all cognitive domains, where people use one thing or process to represent another thing or process. From the perspective of cognition, analogy is a way of metaphorical thinking, which can create similarities among different things, thereby associating any two things and giving them certain similarities [15]. The study found that the grammatical metaphor process of nominalization or lexicalization embodies this feature. Therefore, when people perform language output, they can use grammatical metaphors to give full play to the analogical functions of the brain and flexibly reflect the transformation of human thinking in the cognitive domain, making their language expressions more abundant and diversified. Here are another two examples given by Liu Zhengguang [8] ${ }^{\mathrm{P} 338}$ :

(4)He or she may be a worrier, who bottles up problems so that tensions increase.

(5)How can you stomach the violence in the film today?

In examples (4) and (5), the subject "he" or "she" and "you" are analogized as a container and the object "problems" and "violence" are analogized to the contents of the container. People often use "container" metaphors in language expressions, because many people tend to compare the world to a space when they are aware of objective things, and place human activities in this space. We can see that both the sentence of (4) and (5) are verb grammatical metaphors. Both the "bottles" and the "stomach" in the sentence are used as verbs to express the meaning of "restraint" and "tolerance" respectively. Both examples embody the transformation of human thinking in the cognitive domain. Through analogy, the expression language is vivid. 2.4 Embody the Interactivity of Language

The concept of interaction is a basic view of cognitive semantics. It means that language is gradually formed through cognitive processing based on the perception experience of the objective world and is the result of subjective and objective interaction. Lakoff [16] ${ }^{\text {P119 }}$ et al. believed that "the conceptual system we have is the product of our species as human beings and the result of our interaction with the physical environment and the cultural environment". People live in the social environment, which is also part of the environment. In the activities of interacting with others, there is a process of mutual adaptation. In this process, people gradually formed the concepts and categories of the cognitively objective world, gaining the ability to understand and express. Cognitive grammar believes that semantics have the nature of encyclopedic knowledge, semantics and pragmatics cannot be completely separated, and understanding semantics must take the interaction between human and objective environment into account [17]. The concept of interaction emphasizes that people play a positive and subjective role in the process of understanding the objective world. They think that different people have different conceptual structures because of cognitive differences, thus resulting different categories, schemas and cognitive models, which finally forming different language expression [9]. For example, the two words "glasses" and "spectacles" in English represent the interactive view of language. Some people prefer to use "glasses" while others prefer to use "spectacles". "Glasses" represent their constituent materials, namely the two glasses that make up the glasses, while the "spectacles" showing the function of the glasses, and the word "spect" means "see". Therefore, for the same object, because of people interact with the world in different ways, the way of thinking is different, and they may adopt different language expressions. From the point view of cognitive interaction, grammatical metaphor can better reflect the initiative of cognitive subjects in the process of concept formation and language expression than the congruent form grammatical expression of language, because 
grammatical metaphor reflects the subjective construal factor and the dynamic characteristics of utterance meaning that formed by the conceptualization of the subject in specific situations. Grammatical metaphor, as a re-cognition of human world experience, is more suitable for the best mode of information processing of cognitive ability than the linguistic congruence [18]. Consequently, when people use English to express thoughts, they can use their grammatical metaphors, in the process of interacting with the objective environment, fully exert their subjective energy, making their language expression more flexible, accurate, and appropriate. Please take a look at the following examples:

(6a)It is very cold. Please close the door.

(6b)It is very cold. I don't like the wind.

(6c)It is very cold. Will you please close the door?

(6d)It is very cold. How about a bit less breeze?

It can be seen that in the specific context, the above example sentences have the function of "requesting" others to close the door. The second clause in (6a) is an imperative tone, a linguistic consensus expressing "request". The second clause in (6b) is the statement tone, and the second clauses in (6c) and (6d) are all interrogative mood. They do not directly express the meaning of "requests", but are instead euphemistically performed, which belongs to the metaphor of mood in grammatical metaphor. Therefore, when expressing intention, people can choose the appropriate expression according to the current environment and their relationship with the listener. Look at the following examples:

(7a)Mike should go to attend the conference.

(7b)Mike is supposed to go to attend the conference.

(7c)It's expected that Mike goes to attend the conference.

The above examples have the same semantics. (7a) and (7b) are consistent linguistic expressions, respectively using "should" and "supposed to" for modal meaning. (7c) is a modal metaphor in grammatical metaphor, using the clause "It's expected" to express the same modality. It can be seen that the congruent sentences (7a) and (7b) have lower levels of courtesy, and modal metaphor sentence $(7 \mathrm{c})$ is a very polite expression and also the most easily accepted, as this metaphorical expression helps to reduce the intervention of the spokesman, and saves the listener's face and the right to choose. In certain circumstances, when people are talking to strangers or people with high status, if they want to express different opinions or requests, they can use grammatical metaphors such as $(7 \mathrm{c})$ to show their respect and courtesy to the hearers. Therefore, people should adopt appropriate language expressions according to the requirements of the environment, embodying people's cognition, interaction of language and environment, so as to achieve optimal communication effects.

\section{CONCLUSION}

This paper discusses the functions of English grammatical metaphor from the perspective of cognition.
Grammatical metaphor, especially nominalization grammatical metaphor and verbalization grammatical metaphor, has the function of imagery. When people appropriately use grammatical metaphor in language output, their language can be more cohesive and the imagery function of language can be fully achieved. In different styles, people can fully reflect the conceptual characteristics of language, accurately convey semantics and complete communicative intentions by using grammatical metaphor flexibly. In addition, the proper use of grammatical metaphor in the output of language and adopting analogical metaphorical thinking can reflect the transformation of human thinking in the cognitive domain and make people's language expression richer and more diverse. At the same time, people can fully exert their subjective and actionable actions in the process of interacting with the objective environment and use grammatical metaphors reasonably to make their language expressions more decent and vivid so as to create a discourse that is flexible in terms and abundant in meaning.

\section{REFERENCES}

[1] Halliday, M. A. K. An Introduction to Functional Grammar [M] London: Edward Arnold, 1994.

[2] Fan Wenfang. The Inter-connecting Functions of Nominalization Metaphors [J]. Foreign Languages Research, 1999, (1): 9-12.

[3] Xiong Xi. Coherence Function of Grammatical Metaphor [J]. Journal of Gannan Teachers College, 2003, (4): 118-120.

[4] Sun Chengrong \& Song Desheng. An Empirical Study on the Relationship Between Ideational Grammatical Metaphor and Students' Levels of Text Construction [J]. Foreign Language Research, 2008, (5): 127-129.

[5] Sun Yi \& Chen Lang. The Theoretical Construction of Grammatical Metaphor and Its Reflective Functions for Foreign Language Teaching [J]. Journal of Kunming University of Science and Technology, 2009, (2): 96-100.

[6] Langacker, R. W. Concept, Image and Symbol: The Cognitive Basis of Grammar [M]. Berlin: Mouton de Gruyter, 1991.

[7] Chen Zhong. Researches on Cognitive Linguistics [M]. Ji'nan: Shandong Education Press, 2005.

[8] Liu Zhengguang. Consciousness of Metaphor in Using a Word from Its Noun Form to Verb Form [J]. Foreign Language Teaching and Research, 2000, (5): 335-339.

[9] Wang Yin. Cognitive Linguistics [M]. Shanghai: Shanghai Foreign Language Education Press, 2007.

[10] Gao Hang. Cognitive Grammar and Conversion in Chinese [M] Shanghai: Shanghai Jiao Tong University Press, 2009.

[11] Zhu Yongsheng. On Nominalization, Verbalization and Grammatical Metaphor [J]. Foreign Language Teaching and Research, 2006, (2): 83-90.

[12] Wang Jinjun. The Manifestation of Nominalization in Discourses [J] Foreign Language Research, 2003, (2): 74- 78.

[13] Zhao Yanfang. An Introduction to Cognitive Linguistics [M]. Shanghai: Shanghai Foreign Language Education Press, 2001.

[14] Taylor, J. R. Linguistic Categorization: Prototypes in Linguistic Theory [M]. Oxford: Clarendon Press, 1989.

[15] He Lijun \& Chen Mingfang. A Cognitive Approach to Verbalization [J]. Journal of Xiangtan Normal University, 2006, (3): 140-143.

[16] Lakoff, G. \& M. Johnson. Metaphors We Live By [M]. Chicago: The University of Chicago Press, 1980. 
[17] Langacker, R. W. Foundations of Cognitive Grammar (Vol. I): Theoretical Prerequisites [M]. Stanford: Stanford University Press, 1987.

[18] Jin Na'na \& Chen Zili. Cognitive Effects of Grammatical Metaphor [J]. Foreign Language Teaching and Research, 2004, (1): 25-30. 